\title{
Visualization Study of Terrorist Organizations in Asia Based on UCINET
}

\author{
Mingzhu Zheng a , Qiwu Wu ${ }^{\text {b, }}$ and Lingzhi Jiang ${ }^{c}$ \\ Engineering University of CAPF, Xi'an, 710086, China \\ "Corresponding author.Email: ${ }^{a} 1123722923 @ q q . c o m ;{ }^{b}$ wuqiwu700@163.com; ${ }^{c}$ ustb520@163.com
}

\begin{abstract}
Until 2020, the threat of international terrorist activities still not diminish, extremists accelerated their flight from the Middle East to many countries in Asia and Africa, and terrorist forces around China became extremely active, thus impacting on regional security. Therefore, the analysis of the development trend and characteristics of terrorist organizations in Asia is of great significance to the fight against terrorism in China. This paper analyzes the density and centrality of "terrorist organization-organization" and "terrorist organization-area of operation" networks in Asia by using UCINET based on the social network analysis method. The characteristics of the networked structure of terrorist organizations, the diversification of participants' backgrounds, the increase in regional connectivity and the improvement of organizational planning capabilities were identified, and corresponding strategies were proposed as the theoretical support for counter-terrorism.
\end{abstract}

Keywords: Asia region, Social network analysis, Fight against terrorism, UCINET.

\section{INTRODUCTION}

Since the beginning of the 21 st century, terrorism, one of the non-traditional security threats that the international community is focusing on, has shifted from the previous vertical command to a fragmented terrorist network. Traditional research methods are no longer sufficient to meet our requirements, and the search for rational and effective methods has become the goal of sociologists [1]. This method has been widely used after 9.11 when it was found that social network analysis is important to study the field of counter-terrorism. In this paper, the social network theory is used to study terrorist organizations in Asia, and UCINET is used to analyze the relationship network of terrorist organizations, to obtain their development characteristics and to develop new counter-terrorism strategies based on the conclusions, and to contribute ideas and methods to the fight against terrorism.

\section{BUILDING A NETWORK OF TERRORIST ORGANIZATIONS IN ASIA}

\subsection{Research Methodology}

Social network analysis is a quantitative analysis method developed based on mathematical methods, graph theory, and so on. Although it has been used in research as early as 1981 by Bonnie Erikson [2], it was widely used in the field of counter-terrorism after Valdis Krebs produced models for analyzing terrorist networks [3]. The main indicators of analysis are density and centrality.

\subsection{Data Sources}

The data in this paper is mainly derived from the 108 terrorist organizations on the latest UN sanctions list published on the official UN website in 2020, and with reference to the lists of terrorist organizations designated by major countries and international organizations as of 2019[4], the following 116 major terrorist organizations in the Asian region are obtained. 

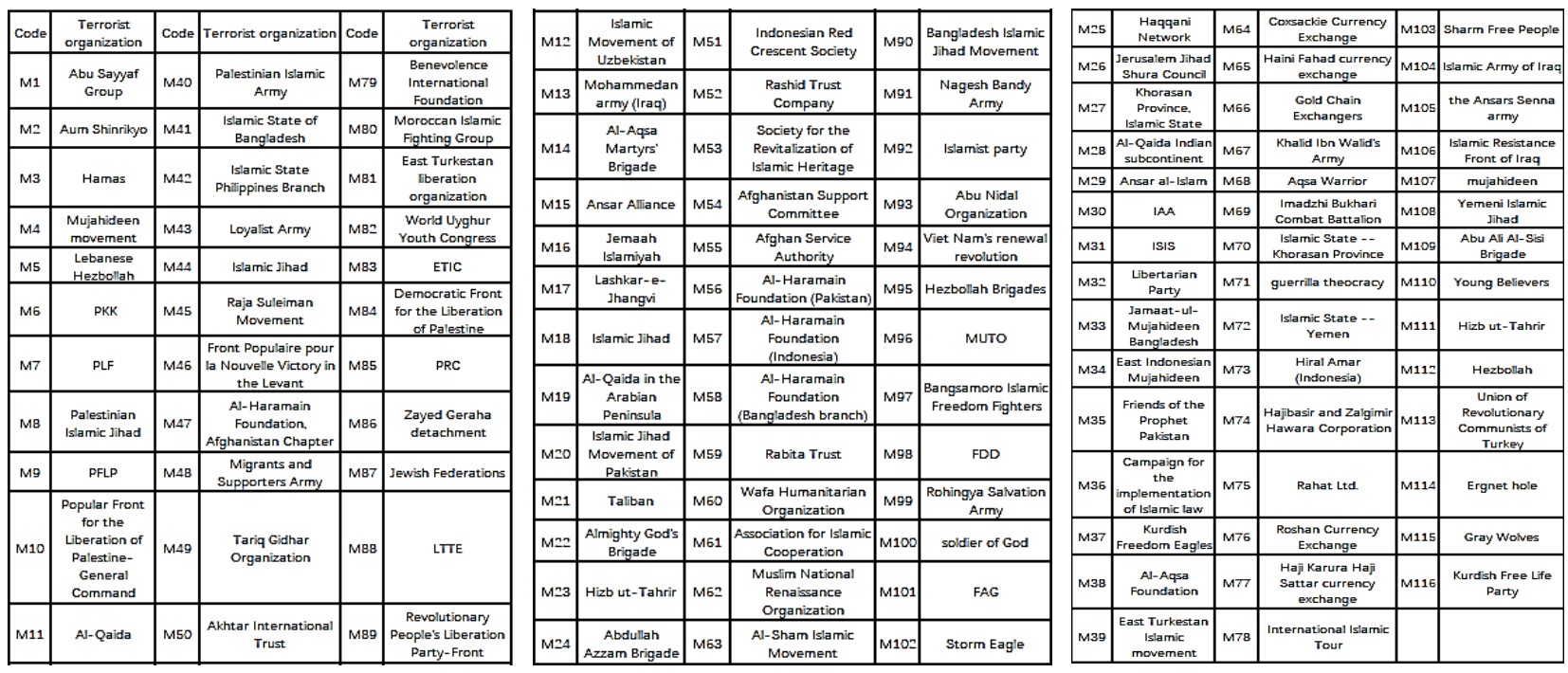

Figure 1 List of terrorist organizations.

\subsection{Building a Matrix of Terrorist Relationships and Network Models}

N1, N2, N3, N4 and N5 represent East, Southeast, Central, West and South Asia, and the following matrix and network models of terrorist "organization-organization" and "organization-region" relations in the Asian region have been constructed based on the data.

\begin{tabular}{|c|c|c|c|c|c|c|c|}
\hline & $\mathrm{M} 1$ & $\mathrm{M} 2$ & $\mathrm{M} 4$ & $\mathrm{M} 5$ & $\cdots$ & $\mathrm{M} 115$ & $\mathrm{M} 116$ \\
\hline $\mathrm{M} 1$ & 1 & 0 & 0 & 0 & $\cdots$ & 0 & 0 \\
\hline $\mathrm{M} 2$ & 0 & 1 & 0 & 0 & $\cdots$ & 0 & 0 \\
\hline $\mathrm{M} 4$ & 0 & 0 & 1 & 0 & $\cdots$ & 0 & 0 \\
\hline $\mathrm{M} 5$ & 0 & 0 & 0 & 1 & $\cdots$ & 0 & 0 \\
\hline$\cdots$ & $\cdots$ & $\cdots$ & $\cdots$ & $\cdots$ & $\cdots$ & $\cdots$ & $\cdots$ \\
\hline $\mathrm{M} 115$ & 0 & 0 & 0 & 0 & $\cdots$ & 1 & 0 \\
\hline $\mathrm{M} 116$ & 0 & 0 & 0 & 0 & $\cdots$ & 0 & 1 \\
\hline
\end{tabular}

Figure 2 Organizational-organizational.

\begin{tabular}{|c|c|c|c|c|c|}
\hline & $\mathrm{N} 1$ & $\mathrm{~N} 2$ & $\mathrm{~N} 3$ & $\mathrm{~N} 4$ & $\mathrm{~N} 5$ \\
\hline $\mathrm{M} 1$ & 0 & 1 & 0 & 0 & 0 \\
\hline $\mathrm{M} 2$ & 1 & 0 & 0 & 0 & 0 \\
\hline $\mathrm{M} 5$ & 0 & 0 & 0 & 1 & 0 \\
\hline$\cdots$ & $\cdots$ & $\cdots$ & $\cdots$ & $\cdots$ & $\cdots$ \\
\hline $\mathrm{M} 115$ & 0 & 0 & 0 & 1 & 0 \\
\hline $\mathrm{M} 116$ & 0 & 0 & 0 & 1 & 0 \\
\hline
\end{tabular}

Figure 3 Organizational-territorial.

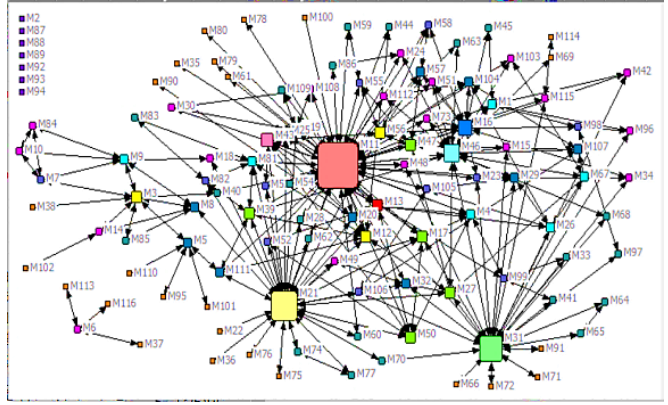

Figure 4 Organization - Organizational.

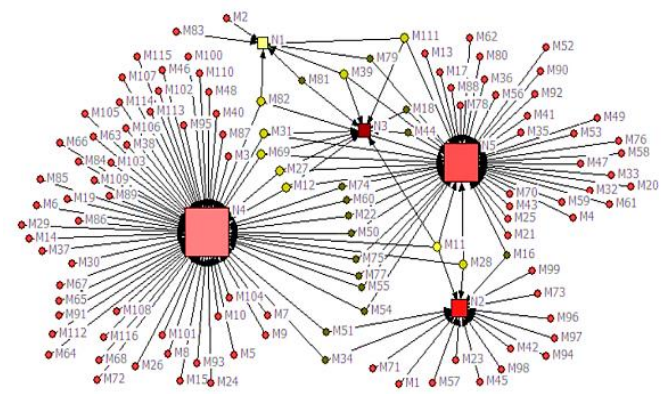

Figure 5 Organization - area of activity.

It can be seen from the figure that the network centered on M11 is the largest in the organizational network, while N4 is the most central in the "organization-area of activity" network, indicating that it is at the core of the network. 

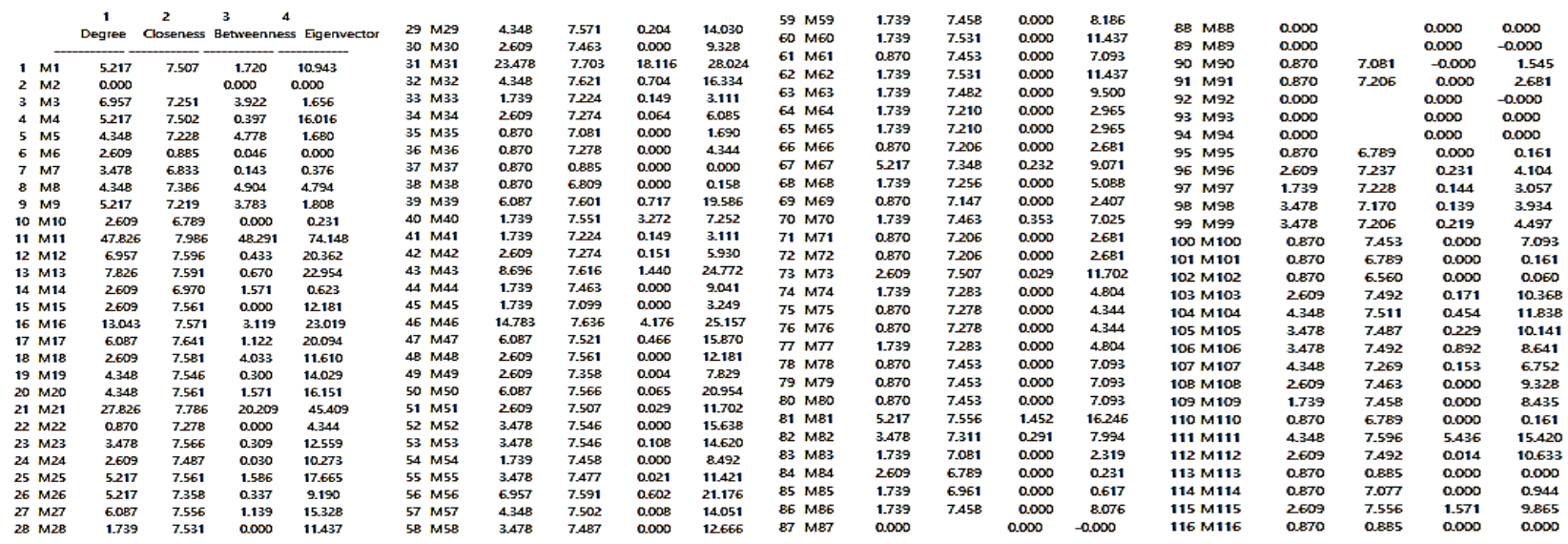

Figure 6 Centrality of "organization-organization" relationship networks.
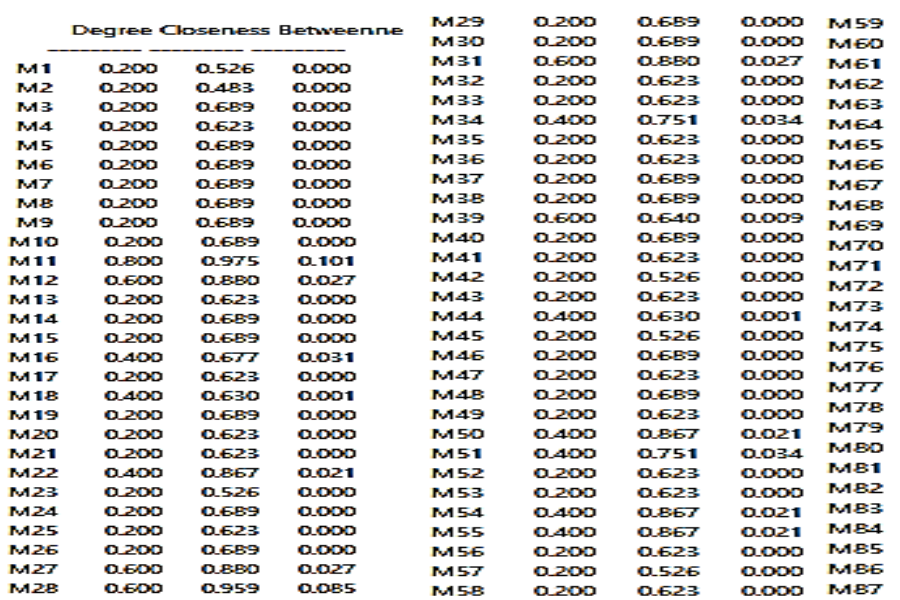

0.200
0.400
0.200
0.200
0.200
0.200
0.200
0.200
0.200
0.200
0.600
0.200
0.200
0.200
0.200
0.400
0.400
0.200
0.400
0.200
0.400
0.200
0.400
0.600
0.200
0.200
0.200
0.200
0.200
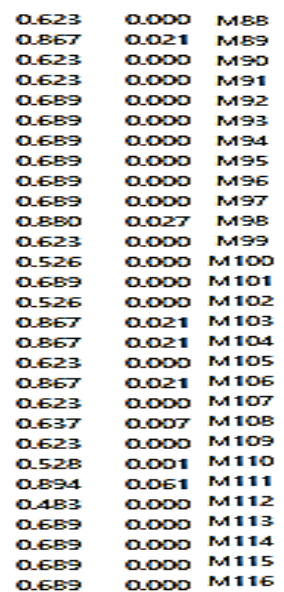

$\begin{array}{lll}0.200 & 0.623 & 0.000 \\ 0.200 & 0.659 & 0.000 \\ 0.200 & 0.623 & 0.000 \\ 0.200 & 0.659 & 0.000 \\ 0.200 & 0.623 & 0.000 \\ 0.200 & 0.659 & 0.000 \\ 0.200 & 0.526 & 0.000 \\ 0.200 & 0.659 & 0.000 \\ 0.200 & 0.526 & 0.000 \\ 0.200 & 0.526 & 0.000 \\ 0.200 & 0.526 & 0.000 \\ 0.200 & 0.526 & 0.000 \\ 0.200 & 0.659 & 0.000 \\ 0.200 & 0.659 & 0.000 \\ 0.200 & 0.659 & 0.000 \\ 0.200 & 0.659 & 0.000 \\ 0.200 & 0.659 & 0.000 \\ 0.200 & 0.659 & 0.000 \\ 0.200 & 0.659 & 0.000 \\ 0.200 & 0.659 & 0.000 \\ 0.200 & 0.659 & 0.000 \\ 0.200 & 0.659 & 0.000 \\ 0200 & 0.659 & 0.000 \\ 0.600 & 0.640 & 0.009 \\ 0.200 & 0.659 & 0.000 \\ 0.200 & 0.659 & 0.000 \\ 0.200 & 0.659 & 0.000 \\ 0.200 & 0.659 & 0.000 \\ 0.200 & 0.659 & 0.000\end{array}$

Figure 7 Terrorist organization centrality of the "Organization-Area of Operation" network.

\section{ANALYSIS OF TERRORIST NETWORKS IN ASIA}

\subsection{Centrality Analysis}

Centrality is an index used to measure the power of a point in a network [5], and there are three types: degree, intermediate, and near-centrality. "Degree centrality" is an index of the local centrality of a point, i.e., its own transactional power; "Intermediate centrality" is an index of the degree to which a point resides between two other points and is an index of control; "Proximity centrality" is an index of the degree to which a point is not controlled by other points [5]. Thus, if a point has a high degree centrality, it has a direct connection with many points and has a high transactional capacity; if it has a high degree of intermediate centrality, it is on the shortest path between many points and is located in an important position in the whole network; if the proximity centrality is high, point has the shortest distance from other points and may reside in the center of the network[6,7].Using the Centrality functions to calculate the centrality of the network of "organization-organizations" and "organization-areas of activity" in the Asian region, the results are as follows.
It can be seen that M11, M21 and M31 have high centrality of all three, indicating that they have direct contact with many organizations and strong ability of controlling; M8 and M111 have high intermediate centrality and low degrees and proximity to centrality, it means that they are an important nodal link for terrorist organizations to connect.

It can be seen that M11 has the highest values of the three centrality values and is the core organization in the network. M12, M28, M27, M31, M69 and M82 all have a degree centrality of 0.6 . Comparing the proximity centrality shows that M28 and M82 have a high proximity and intermediate centrality, indicating that they are key organizations in the network and have more control over other organizations; whereas, M12, M27, M31 and M69 have a low intermediate centrality, indicating that they have less control over the network members. 


\begin{tabular}{llll} 
& \multicolumn{2}{c}{ Degree Closeness Betweenne } \\
N1 & 0.060 & 0.337 & 0.038 \\
N2 & 0.147 & 0.378 & 0.195 \\
N3 & 0.086 & 0.369 & 0.027 \\
N4 & 0.578 & 0.559 & 0.699 \\
N5 & 0.422 & 0.481 & 0.495
\end{tabular}

Figure 8 Regional centrality of the "Organization-Area of Activity" network.

As can be seen from the results, N4 and N5 have the highest centrality and are the most important in the network; the other three are not relatively less centric. On the whole, the regions are increasingly well connected.

\subsection{Network Density Analysis}

The density reflects the closeness of the relationship between the components. To calculate the network density, we first need to calculate the shortcut distance of each point. The network centered on M11 is analyzed, and after calculating the shortcut distance, organizations with a shortcut distance of less than 2 to the core organization (degree centrality $\geq 10$ ) are selected to establish a relationship matrix and calculate their average distance, cohesion index and network density. As shown in figures:

\begin{tabular}{|c|c|c|c|}
\hline $\begin{array}{c}\text { Core } \\
\text { organization }\end{array}$ & $\begin{array}{c}\text { Average } \\
\text { distance }\end{array}$ & $\begin{array}{c}\text { Cohesion } \\
\text { index }\end{array}$ & Density \\
\hline M11 & 2.484 & 0.437 & 0.0494 \\
\hline M16 & 2.14 & 0.481 & 0.0744 \\
\hline M21 & 2.323 & 0.464 & 0.0615 \\
\hline M31 & 2.276 & 0.469 & 0.0622 \\
\hline M46 & 2.252 & 0.474 & 0.0628 \\
\hline
\end{tabular}

Figure 9 Table of values for three parameters.

Overall, the cohesion index and network density of the five networks are low (much less than 1), indicating that terrorist organizations in Asia are becoming more widely and loosely globalized and more mobile and flexible in their terrorist activities.

\section{CHARACTERISTICS OF ASIAN TERRORIST ORGANIZATIONS AND COUNTER-TERRORISM STRATEGIES}

\subsection{New Features of Terrorist Organizations in Asia}

First, the structure of terrorist organizations has become networked. Due to the popularization of information technology, the structure of terrorist organizations from the previous vertical organizational structure and hierarchy into a network structure with decentralized decision-making power and no affiliation to each other, with strong flexibility and organizational capacity, which brings great difficulty to the action against terrorist forces[8].

Secondly, the regional linkage of terrorist activities is enhanced. The development of information technology has made it easier and easier for terrorists to communicate and liaise[6], and the loose network structure is conducive to the change of regions and methods of terrorist activities according to the needs, and the results of regional centrality show that regional links are becoming closer and closer and the connectivity is greatly enhanced.

Thirdly, the background of participants in terrorist activities is diversified. As terrorism is adept at using the Internet and social media to disseminate terrorist ideas, those involved in terrorist activities or potential terrorists with radicalized ideas have become common, young and diverse[8].

Fourthly, the planning capacity of terrorist organizations has been enhanced. In recent years, the means of terrorist propaganda have kept pace with the times, and there are strict channels for the circulation of funds, so that police checks can be cleverly avoided. At the same time, the terrorists' lurking cycle and planning process have become longer, making the planning of terrorist attacks more rigorous and the difficulty of combating them greatly enhanced [6].

\subsection{Counter-terrorism Strategy}

First, we have intensified our efforts to combat terrorism through the Internet. With the help of new media platforms, terrorist organizations can carry out all kinds of terrorist information network dissemination activities, and the spread of terrorist ideas is accelerated. Therefore, the State should strengthen online and offline propaganda, enhance public awareness of network security, while strengthening new media legislation and regulation to block the network transmission of terrorist information[9].

Secondly, it is necessary to strengthen the collection and sharing of intelligence on terrorism. Terrorist activities are covert in nature, so it is necessary to improve intelligence investigation methods, enhance the ability to obtain intelligence, flexibly adopt various kinds of high technology to obtain intelligence information, and at the same time pay attention to the sharing of information resources, broaden intelligence collection channels and facilitate the acquisition of information by counter-terrorism intelligence departments[10].

Thirdly, we attach great importance to international counter-terrorism cooperation. With the globalization of terrorist activities in recent years, counter-terrorism cooperation has become an irresistible trend. It is therefore necessary to strengthen counter-terrorism 
cooperation with the international community on the basis of the principles of equality, fairness, mutual trust and win-win cooperation, and to work together to strengthen counter-terrorism mechanisms, so as to create a climate of friendship and cooperation and avoid the further spread of terrorist forces.

Fourthly, the Government should do a good job in combating terrorism at the border and controlling the situation in the region. Many terrorists from outside China have infiltrated our borders and are colluding with our separatist forces; therefore, it is necessary to strengthen military deterrence and preparedness in key areas, organize regular patrols, conduct regular anti-terrorist drills and maintain a high-handed posture against terrorist forces.

\section{CONCLUSION}

The issue of terrorism involves all aspects of international security, and a comprehensive understanding of terrorism and a comprehensive plan for combating it are essential. The study of the characteristics of terrorist organizations in Asia based on the theory of social network analysis can help us formulate effective strategies to win the war against terrorism.

\section{ACKNOWLEDGMENTS}

This work is supported by the Natural Science Basic Research Plan in Shanxi Province of China (No.2020JM-361), the Young and middle-aged scientific research backbone projects of Engineering University of PAP (No.KYGG201905) and the basic research foundation project of Engineering University of PAP (No.WJY201920, No.WJY202019), military theory research project of Engineering University of PAP (No.JLY2020085), education and teaching fund project of Engineering University of PAP (No.WJJ202039), the PAP's Military Scientific Research Mandatory Project (No.WJ2020A020047, No.WJ2020A020048, No.WJ2020A020029,

\section{REFERENCES}

[1] Liu Zhiwei, Counterterrorism in Chinese Perspective and Extraterritorial Reference,Beijing: Chinese People's Public Security University Press, 2019.

[2] Erickson,B.H. Secret Societies and Social Structure, Social Forces 1981,60(1): 188-210.

[3] Sparrow,M.K. The application of network analysis to criminal intelligence:An assessment of the prospects, Social Networks 1991,(13):251-274.

[4] Ji Zhiye, Feng Zhongping, Fu Xiaoqiang, Yearbook of International Terrorism and the Fight Against Terrorism, Beijing: Current Affairs Press, 2018.

[5] Liu Jun, Overall network analysis lecture: UCINET Software Practical Guide, Shanghai: Shanghai People's Publishing House, 2009.

[6] Yao Jianlong, Zhou Zhou, An Introduction to Counterterrorism, Beijing:Peking University Press, 2018.

[7] Ji Zhiye, Feng Zhongping, Fu Xiaoqiang, Yearbook of International Terrorism and the Fight Against Terrorism, Beijing: Current Affairs Press, 2017.

[8] Qian Xuewen, Studies on terrorism in the Middle East, Shanghai: Current Affairs Press, 2013.

[9] Han Meichao, The Network Dissemination of Terrorist Information and Countermeasures Against the Background of New Media, Chinese People's Public Security University, 2020.

[10] Fu Julei, Terrorism and Counter-Terrorism Strategies Based on Open Source Intelligence: Taking the East Turkistan Terrorist Activity as an Example, Hunan: Graduate School of National University of Defense Technology, 2014. No.WJ2020A020049). 